\title{
Upregulation of Kiss-1 and Gpr54 Genes Expression in Pituitary of Male Rats Following the Central Administration of Neuropeptide $\mathrm{Y}$
}

\author{
Vahid Azizi ${ }^{1 *}$, Shahrbanoo Oryan², Homayuon Khazali' ${ }^{2}$ Abdolkarim Hosseini ${ }^{1}$ \\ 'Department of Animal Sciences and Biotechnology, Faculty of Life Sciences and Biotechnology, Shahid Beheshti \\ University, Tehran, Iran \\ ${ }^{2}$ Department of Animal Biology, Faculty of Biological Sciences, Kharazmi University, Tehran, Iran
}

\section{*Correspondence to Vahid Azizi \\ Department of Animal Sciences and Biotechnology, Faculty of Life Sciences and Biotechnology, Shahid Beheshti University, Tehran, Iran Tel: +982129905924 \\ Fax: +982122431664 \\ E-mail:v_azizi@sbu.ac.ir}

Received October 15, 2019 Accepted December 22, 2019 Published online December 31, 2019

\begin{abstract}
Introduction: The neuropeptide $Y(N P Y)$ in the neural circuits of the hypothalamus has a stimulating effect on reproductive activities in mammals. Kisspeptin (KiSS1) is a quintessential neurotransmitter in the reproductive axis which directly stimulates gonadotropin-releasing hormone neurons in the hypothalamus. The distribution of KiSS1 expressing cells in the pituitary was described previously. Despite earlier reports showing the KiSS1 receptor, G-protein coupled receptor 54 (GPR54) expression in the pituitary, the potential physiological roles of kisspeptin at this gland have remained obscure. Accordingly, this study investigated the role of NPY on the relative expression of Kiss 1 and Gpr54 genes in the pituitary gland in male Wistar rats.

Methods: In general, 20 male Wistar rats weighing 200-250 g in 4 groups (5 in each group) received saline, NPY (2.3 nM), BIBP3226 (NPY receptor antagonist, $7.8 \mathrm{nM})$, and NPY+ BIBP3226. Then, they received the simultaneous injection of these molecules through the third ventricle of the brain. Finally, the relative mean expressions of Kiss 1 and Gpr54 genes in the anterior pituitary were quantitatively analyzed by the real-time polymerase chain reaction.

Results: The central injection of NPY increased the relative mean expressions of Kiss 1 and Gpr54 genes in the pituitary gland compared to the control group although the injection of BIBP3226 eradicated these effects. However, the gene expression of Gpr54 in the rats receiving NPY coupled with BIBP3226 in hypophysis in comparison to the group receiving only NPY demonstrated a significant reduction $(P<0.05)$.

Conclusion: Overall, the central injection of NPY stimulated the gene expression of Kiss 1 and Gpr54 in the pituitary gland.

Keywords: Neuropeptide Y, BIBP3226, Kisspeptin, GPR54, Gene expression, Pituitary gland
\end{abstract}

Please cite this article as follows: Azizi V, Oryan S, Khazali H, Hosseini A. Upregulation of Kiss-1 and Gpr54 Genes Expression in Pituitary of Male Rats Following the Central Administration of Neuropeptide Y. Int J Basic Sci Med. 2019;4(4):137142. doi:10.34172/ ijbms.2019.03.

\begin{abstract}
Introduction
The complex structure of neuronalhormonal mechanisms would influence the release rate of gonadotropin-releasing hormone $(\mathrm{GnRH})$, luteinizing hormone (LH), and gonadal hormones. In the recent decade, most research has focused on the hypothalamic-pituitary-gonadal axis function in kisspeptin (KiSS1) and G-protein coupled receptor 54 (GPR54). KiSS1belongs to the RF-amide family which is produced by the proteolytic cleavage of the pro-kisspeptin precursor, encoded by the Kiss 1 gene. ${ }^{1-3}$
\end{abstract}

The KiSS1/GPR54 system regulates and organizes the activity of hypothalamic GnRH neurons and has been identified as one of the most potential pathways for the development of sexual maturation pathways. $^{4-7} \quad$ Hypogonadotropic hypogonadism is caused by mutations in Kiss 1 and Gpr54 genes. In this disease, the symptoms of hypogonadism resulted from a decrease in the pituitary gonadotropins are observable. . $^{2,8-10}$

Given that the Gpr54 gene in addition to the central nervous system is expressed in peripheral tissues, the presence of non-

(C) 2019 The Author(s); Published by Zabol University of Medical Sciences. This is an open-access article distributed under the terms of the Creative Commons Attribution License (http://creativecommons.org/licenses/by/4.0), which permits unrestricted use, distribution, and reproduction in any medium, provided the original work is properly cited. 
neural KiSS1-secreting and Gpr54 gene expressing cells in the pituitary is likely. ${ }^{11,12}$

Low levels of gonadotropins and testosterone are observed in male rats that are mutated in the Gpr54 gene. The plasma levels of luteinizing hormone (LH) and follicle-stimulating hormone (FSH) are low in these rats. Nevertheless, since there is still some LH and FSH secretions, pituitary gonadotropic cells are still somewhat functionally active in these mutants. ${ }^{13}$

Neuropeptide Y (NPY) is considered as a powerful 36 amino-acid orexigenic peptide that is expressed in the distinct areas of the brain, especially in the arcuate nucleus of the hypothalamus. ${ }^{14}$ Previous reports indicated that NPY neurons directly influence GnRH cells in the hypothalamus. Reciprocally, NPY knockout mice do not secrete a normal level of $\mathrm{LH}^{15}$

There is no study concerning the NPY molecular interaction and Kiss1/GPR54 signaling pathway in male Wistar rats at the pituitary level. In this study, the basis of the hypothesis is that NPY acts independently of GnRH neurons through the effect of the pituitary Kiss1/GPR54 system on the reproductive axis. To this end, this study examined the effects of NPY and BIBP3226 and their concomitant injections on the relative expression of Kiss 1 and Gpr54 genes in the pituitary in order to determine the molecular interaction of NPY and KiSS1 in regulating pituitary-gonadal axis activity. In effect, the study aimed to identify the expressions of the Kiss 1 gene and its receptor (GPR54) in the reproductive axis at the pituitary level (i.e., outside the hypothalamus).

\section{Materials and Methods \\ Animals \\ In the current research, the Neuroscience Research Center of Shahid Beheshti University, Iran provided the male Wistar rats $(n=20)$ weighing $200-250 \mathrm{~g}$. The animals were placed in cages. During the project, they were kept under the following controlled environments: the relative humidity of $50 \%$, the ambient temperature of $22 \pm 2{ }^{\circ} \mathrm{C}$, and photoperiod of 12:12 darkness and light. Moreover, the animals did not have any limitations in terms of water and food availability.}

Intracerebroventricular Cannulation and Injections

The rats were anesthetized deeply by a mixture of xylazine $\left(10 \mathrm{mg} \mathrm{kg}^{-1}\right)$ and ketamine $\left(80 \mathrm{mg} \mathrm{kg}^{-1}\right)$. It was carried out for conducting cannulation and intra-cerebroventricular injection. In a nutshell, the rats underwent stereotaxic surgery for identifying the coordinates of the injection zone after anesthetization. Next, the area for cannulation was specified ${ }^{15}$ based on the coordinates provided in the Paxinos and Watson atlas (anterior-posterior $=-2.3$, midline $=0.0$, and dorsoventral $=6.5$ ). After inserting the cannula into the brains of the animals, they were slowly transferred to their individual sterile cages. Then, the rats were maintained in the animal room for one week in order to undergo the recovery period. Having gone through this one-week recovery period, they were subdivided into four groups which intracerebroventricularly received $3 \mu \mathrm{L}$ vehicle, NPY [YY-36-NH2] (2.3 nmol), BIBP3226 [RR-1] $(7.8 \mathrm{nmol})$, and BIBP3226 $(7.8 \mathrm{nmol})+\mathrm{NPY}(2.3 \mathrm{nmol})$ for gene expression analysis $(n=5$ per groups). Next, BIBP3226 (GL Biochem Ltd, Shanghai, China) and NPY (GL Biochem Ltd, Shanghai, China) were dissolved in a saline for the micro-injection of intracerebroventricular. By the microinjection method, the solutions were slowly injected into the third ventricle of the rodents in one minute, followed by utilizing the tube of polyethylene and the syringe of Hamilton ( $5 \mu \mathrm{L}$, USA).

\section{Brain Dissection and Hypophysis Isolation}

At the final stage of the experiment, the animals were anesthetized deeply with an amalgam of xylazine (10 $\mathrm{mg} \mathrm{kg}$ ) and ketamine $\left(80 \mathrm{mg} \mathrm{kg}^{-1}\right)$. Next, the removal of the brain took place very quickly with the excision of hypophysis. Then, the tissues were promptly immersed in the nitrogen liquid and kept under a temperature of $-80^{\circ} \mathrm{C}$ until the implementation of further research.

\section{The RNA Extraction and Gene Expression}

From the pituitary samples of the experimental groups, the total RNA was elicited using the GeneJet RNA Purification Kit (Thermo Scientific, USA). In addition, the total RNA was treated with DNase I (Thermo Scientific, USA) for eliminating the probability of DNA infection. Then, the gleaned total RNA yield was determined by a spectrophotometer at $260 \mathrm{~nm}$. Next, the purified RNA (1 $\mu \mathrm{g})$ was adopted by the utilization of the RevertAid First Strand cDNA Synthesis Kit (Thermo Scientific, USA) for the cDNA synthesis. All the counted phases took place in accordance with the instructions of the manufacturer.

\section{Quantitative Real-time Polymerase Chain Reaction (qPCR)}

The procedure was adopted to gauge the target genes with the specified primers of each gene (Table 1). The

Table 1. Primers Used for qPCR

\begin{tabular}{|c|c|c|c|c|}
\hline Gene & Primer Sequence $\left(5^{\prime}-3^{\prime}\right)$ & & Accession Number & Amplicon Size (bp) \\
\hline Kiss 1 & F:TGGCAAAAGTGAAGCCTGGA & R:TCTCTGCATACCGCGATTCC & NM_181692 & 80 \\
\hline Gpr54 & F: GGTGCTGGGAGACTTCATGT & R: AGTGGCACATGTGGCTTG & NM_023992 & 105 \\
\hline GAPDH & F:TGATGGGTGTGAACCACGAG & R:GCCCTTCCACAATGCCAAAG & NM_017008 & 106 \\
\hline
\end{tabular}

Note. qPCR: Quantitative real-time polymerase chain reaction; Kiss1: Kisspeptin; Gpr54: G-protein coupled receptor 54; GAPDH: Glyceraldehyde 3-phosphate dehydrogenase; Primer orientation: F: Forward; R: Reverse. 
relative expression of each specimen was delineated with SYBR $^{\circledast}$ Premix Ex Taq ${ }^{\text {TM }}$ II (Takara, Japan) by the use of the real-time PCR device (Corbett Research, Australia). Further, PCR was carried out for each given transcript in a duplicate manner with a final volume of $20 \mu \mathrm{L}$ based upon the following thermal cycle: 10 minutes at $95^{\circ} \mathrm{C}, 40$ cycles of $95^{\circ} \mathrm{C}, 60^{\circ} \mathrm{C}$, and $72^{\circ} \mathrm{C}$ each for 30 seconds, respectively. Based on efficiency, for each reaction, the analysis of the transcript level was rectified by the calculation of the cycle threshold (Ct). Next, $\Delta \mathrm{Ct}$ was calculated by the deduction of the calibrator average from the $\mathrm{Ct}$ of each gene. Accordingly, the calculation of the relative expression of each target gene was made compared with the reference gene using formula $2^{-\Delta \Delta \mathrm{Ct} 16}$.

\section{Statistical Analysis}

The gleaned data from the experimental groups were calculated with SPSS software, version 25. The elicited results were probed and expressed as the mean \pm standard error from the mean (SEM). Then, the KolmogorovSmirnov test was used to test the normality distribution of the results. Furthermore, one-way variance analysis and Tukey post hoc test were used to compare the results. Differences between data with $P<0.05$ were deemed to be significant and charts were drawn with the use of GraphPad Prism software, version 8.

\section{Results}

The Effects of Intracerebroventricular Injection of NPY and BIBP3226 on Kiss1 Gene Expression

The analyses of the obtained results from qPCR showed that the central injection of NPY increased the relative gene expression of Kiss1 $(P<0.001)$. On the other hand, the injection of BIBP3226 decreased the gene expression level of Kiss 1 in a significant way $(P<0.01)$. In addition, the combined injection of BIBP3226 and NPY decreased the gene expression of Kiss 1 significantly $(P<0.01)$. It was suggested that pretreatment with BIBP3226 could block the simulative effects of NPY on the transcription level of the Kiss 1 gene to some extent.

The expression of the Kiss1 gene demonstrated a significant reduction in the group receiving BIBP3226 $v s$. the NPY-injected group $(P>0.001)$, indicating that BIBP3226 was capable of obviating the stimulatory effect of neuropeptide $\mathrm{Y}$ on the Kiss1 gene expression. The concomitant injections of NPY and BIBP3226 revealed similar results compared to the NPY injection although it did not result in any significant changes compared to the BIBP3226 group (Figure 1).

The Effects of the Intracerebroventricular Injection of NPY and BIBP3226 on Gpr54 Gene Expression

The relative gene expression of Gpr54 in the NPYtreated group showed a significant difference with that of the control group $(P<0.001)$. The central injection of BIBP3226 increased the gene expression level of

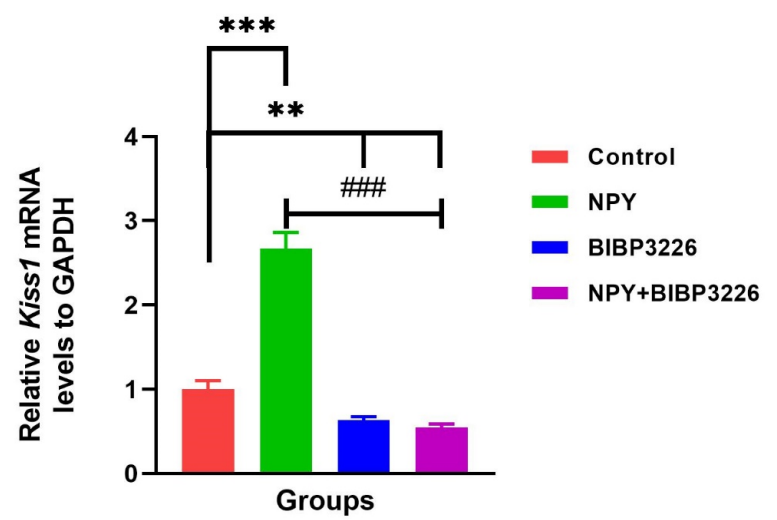

Figure 1. Relative Expression of Kiss $1 \mathrm{mRNA}$ in the Rat Pituitary Gland After the Administration of NPY, BIBP3226, and Coadministration of NPY and BIBP3226 ( $n=5$ in each group).

Note. Kiss 1: Kisspeptin; mRNA: Messenger ribonucleic acid; NPY: Neuropeptide Y; Data are shown as mean \pm SEM. ${ }^{* *} P<0.01$, ${ }^{* * *} P<0.001$ compared to the control group, and ${ }^{\# \#} P<0.001$ compared to the NPY group.

Gpr54 $(P<0.01)$. However, pretreatment with BIBP3226 decreased the simulative effects of NPY on Gpr54 gene transcription so that at the time of the combined injection of the drugs, a significant difference was observed at the level of Gpr54 gene expression in comparison with that of the control group.

The results further represented that the injection of the NPY receptor antagonist was able to significantly inhibit NPY stimulatory effects on Gpr54 gene expression in the pituitary gland $(P>0.01)$ because the co-injection of NPY and BIBP3226 significantly decreased Gpr54 gene expression compared to the NPY group $(P>0.01)$. Eventually, this group revealed a significant decline in Gpr54 gene expression $(P>0.001)$ in comparison to the group receiving BIBP3226 (Figure 2).

\section{Discussion}

Studies unveiled that high levels of NPY mRNA were expressed in the peripheral organs of the rats. This signals the production of NPY by non-neural cells in the body. ${ }^{18}$ The results of the present study confirmed that NPY in the pituitary gland leads to a significant elevation in Kiss 1 and Gpr54 gene expressions. Further, NPY plays a role in regulating reproductive activity outside the hypothalamus. This neuropeptide enhances the binding of GnRH to its receptor in LH-secreting cells in the pituitary gland. ${ }^{19}$

The molecular findings in this study also confirmed the interaction of the hormonal data on KiSS1 and $\mathrm{NPY}^{20}$ and pointed to the fact that the interaction of these drugs requires the presence of non-neuronal cells which produce isoforms from KiSS1 and its receptor in the gonadotroph cells of the pituitary gland. This system justifies the effect of KiSS1 on the production and secretion of LH, as well as the secretory and feedback 


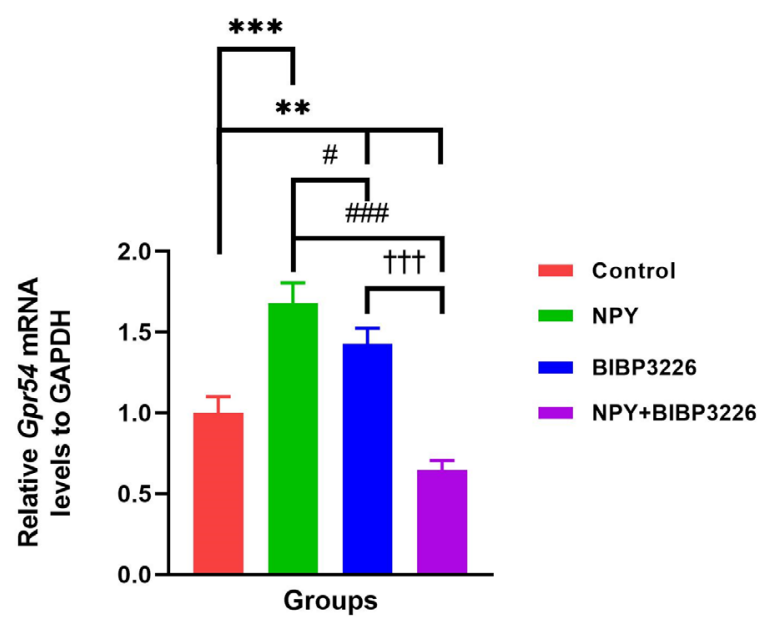

Figure 2. Relative Expression of Gpr54 mRNA in the Rat Pituitary Gland After the Administration of NPY, BIBP3226, and Coadministration of NPY and BIBP3226 ( $n=5$ in each group). Note. Gpr54: G-protein coupled receptor 54; mRNA: Messenger ribonucleic acid; NPY: Neuropeptide Y; Data are shown as mean \pm SEM. ${ }^{* *} P<0.01,{ }^{* * *} P<0.001$ compared to control group, ${ }^{*} P<0.05,{ }^{* \# \#}$ $P<0.001$ compared to the NPY group, and ${ }^{+++} P<0.001$ compared to the BIBP3226 group.

regulation of gonadal hormones at the pituitary level. The present findings highlight that to facilitate the effect of $\mathrm{GnRH}$ on gonadotrophic cells in the anterior pituitary, the mediating molecules function through ways such as enhancing receptor gene expression, enhancing mingling potency to the receptors, or removing the receptors from the potential desensitization state when the ligand is continuously present in the intercellular fluid. One of these mediating molecules is NPY that acts outside the central nervous system and at the pituitary level by boosting the expression of the Kiss1 gene and its receptor. On the other hand, the central injection of BIBP3226 significantly diminished the expression of the Kiss 1 gene in the pituitary. Moreover, in the co-injection with NPY, it could significantly reduce the stimulatory effects of NPY in this regard. The facilitating effects of NPY on the stimulation of $\mathrm{LH}$ secretion by GnRH were reported by Bauer-Dantoin et al, which is in harmony with our results. ${ }^{21}$

The purpose of the present study was to determine whether, in addition to the upstream pathways in the hypothalamus, the regulation of the KiSS1/GPR54 signaling pathway is mediated at the pituitary level or not. The injection of BIBP3226 with NPY inhibited the NPY stimulatory effects on the relative mean expression of the Kiss 1 gene and significantly reduced the relative expression of the Kiss 1 gene in the pituitary compared to the control group. In fact, NPY through the induction of constructive KiSS1 secretion cells in the target cells somehow augments its synergistic effects on the reproductive axis.
The experiment of Navarro et al gives testimony to this, ${ }^{7}$ indicating that these two stimulatory neuropeptides can have synergistic effects on reproductive processes.

BIBP3226 and the concomitant injection of BIBP3226 and NPY, unlike NPY, have a negative significant effect on the expression of the Kiss 1 gene in the pituitary. Crowley et al reported that NPY works directly on the pituitary gland both alone and in collaboration with luteinizing hormone-releasing hormone to moderate $\mathrm{LH}$ secretion. ${ }^{22}$ Our findings are consistent with the results of the above-mentioned study due to the effects of regulatory neuropeptides extra-cerebrally and at the pituitary levels. Therefore, the NPY receptors do exist in anterior pituitary gonadotroph cells and can be affected by the agonistic and antagonistic drugs of the NPY receptor. They further can alter cell activity after running the intracellular transduction pathway up to the transcriptional level from the receptor genes. ${ }^{23,24}$ In the current experiment, gonadotroph cells designed and implemented the gene expression of KiSS1 signaling by receiving antagonists Y1, namely, BIBP3226 in order to inhibit post-translation processes.

Our results showed that NPY in the pituitary gland significantly increased Kiss 1 gene expression. This may boil down to the fact that there was sufficient time to activate compensatory mechanisms to renew the acceptable levels of the receptor and provide the receptor sensitization mechanism with KiSS1 as a specific ligand. The increased receptor number in the pituitary gland is a consequence of this event. Gonadotrophs may also have increased their receptor gene expression to induce an increased sensitivity to the ligand (KiSS1) and be responsive to the increased concentration of KiSS1 which was induced under the influence of NPY. In fact, this finding is partly consistent with that of the previous research which reported a significant increase in GPR54 following the central injection of ghrelin, 48 hours before starvation in adult rats or 72 hours after starvation in immature male and female rats. ${ }^{25-27}$ Specifically, NPY is closely linked to food intake, energy balance, and hunger. In terms of its metabolic function and food-finding behavior, it also interacts with ghrelin and leptin. ${ }^{26,28,29}$

Simultaneous injection of NPY and BIBP3226 reduced the expression of the Gpr54 gene in the pituitary gland. In this case, the synergistic or combined effects of either drug alone were not observable. Nonetheless, contrary to what was expected, the developed behavior of pituitary gonadotrophs was observed regarding receiving both substances to inhibit receptor gene expression. The interaction of $\mathrm{Y} 1$ receptor agonist and antagonist function has activated which secondary peaks in pituitary gonadotropic cells is a particular research desideratum that warrants further research. ${ }^{30}$ 


\section{Conclusion}

Data from qPCR showed that the injection of NPY significantly increased the gene expression of Kiss 1 and Gpr54 in the pituitary while treatment with BIBP3226 blocked the stimulatory effects of NPY on the gene expression of Kiss1 and Gpr54 in this gland.

\section{Ethical Approval}

The Ethics Committee of Shahid Beheshti University confirmed the validity of this project (ethical code: IR.SBU.96.453).

\section{Conflict of Interest Disclosure}

Hereby the authors confirm that there is no conflict of interests in the present research.

\section{Authors' Contribution}

VA: Project development, Conducting experiments, Data collection, Literature search, Manuscript writing/editing. SO: Project development, Supervision, Supplying financial resources, equipment, space, and personnel vital to the project, Provide biological materials and reagents, Manuscript editing.

HK: Project development, Supervision, Supplying financial resources, equipment, space, and personnel vital to the project, Provide biological materials and reagents, Manuscript editing.

AH: Data analysis, Literature search, Manuscript writing/ editing.

\section{Acknowledgements}

The authors would like to thank the National Institute of Genetic Engineering and Biotechnology for the provided chemicals and laboratory facilities.

\section{References}

1. Kotani M, Detheux M, Vandenbogaerde A, et al. The metastasis suppressor gene KiSS-1 encodes kisspeptins, the natural ligands of the orphan $G$ protein-coupled receptor GPR54. J Biol Chem. 2001;276(37):34631-34636. doi:10.1074/jbc.M104847200

2. Popa SM, Clifton DK, Steiner RA. The role of kisspeptins and GPR54 in the neuroendocrine regulation of reproduction. Annu Rev Physiol. 2008;70:213-238. doi:10.1146/annurev. physiol.70.113006.100540

3. Oakley AE, Clifton DK, Steiner RA. Kisspeptin signaling in the brain. Endocr Rev. 2009;30(6):713-743. doi:10.1210/ er.2009-0005

4. Navarro VM, Castellano JM, Fernández-Fernández R, et al. Developmental and hormonally regulated messenger ribonucleic acid expression of KiSS-1 and its putative receptor, GPR54, in rat hypothalamus and potent luteinizing hormone-releasing activity of KiSS-1 peptide. Endocrinology. 2004;145(10):4565-4574. doi:10.1210/ en.2004-0413

5. Han SK, Gottsch ML, Lee KJ, et al. Activation of gonadotropin-releasing hormone neurons by kisspeptin as a neuroendocrine switch for the onset of puberty. J Neurosci. 2005;25(49):11349-11356. doi:10.1523/ jneurosci.3328-05.2005

6. Kinoshita $\mathrm{M}$, Tsukamura $\mathrm{H}$, Adachi $\mathrm{S}$, et al. Involvement of central metastin in the regulation of preovulatory luteinizing hormone surge and estrous cyclicity in female rats. Endocrinology. 2005;146(10):4431-4436. doi:10.1210/ en.2005-0195

7. Navarro VM, Castellano JM, Fernández-Fernández R, et al. Characterization of the potent luteinizing hormonereleasing activity of KiSS-1 peptide, the natural ligand of GPR54. Endocrinology. 2005;146(1):156-163. doi:10.1210/ en.2004-0836

8. Seminara SB, Messager S, Chatzidaki EE, et al. The GPR54 gene as a regulator of puberty. N Engl J Med. 2003;349(17):1614-1627. doi:10.1056/NEJMoa035322

9. de Roux N, Genin E, Carel JC, Matsuda F, Chaussain JL, Milgrom E. Hypogonadotropic hypogonadism due to loss of function of the KiSS1-derived peptide receptor GPR54. Proc Natl Acad Sci U S A. 2003;100(19):10972-10976. doi:10.1073/pnas.1834399100

10. d'Anglemont de Tassigny X, Fagg LA, Dixon JP, et al. Hypogonadotropic hypogonadism in mice lacking a functional Kiss1 gene. Proc Natl Acad Sci U S A. 2007;104(25):10714-10719. doi:10.1073/pnas.0704114104

11. Ohtaki T, Shintani Y, Honda S, et al. Metastasis suppressor gene KiSS-1 encodes peptide ligand of a G-proteincoupled receptor. Nature. 2001;411(6837):613-617. doi:10.1038/35079135

12. Mikkelsen JD, Simonneaux V. The neuroanatomy of the kisspeptin system in the mammalian brain. Peptides. 2009;30(1):26-33. doi:10.1016/j.peptides.2008.09.004

13. Funes S, Hedrick JA, Vassileva G, et al. The KiSS-1 receptor GPR54 is essential for the development of the murine reproductive system. Biochem Biophys Res Commun. 2003;312(4):1357-1363. doi:10.1016/j.bbrc.2003.11.066

14. Allen YS, Adrian TE, Allen JM, et al. Neuropeptide Y distribution in the rat brain. Science. 1983;221(4613):877879. doi:10.1126/science.6136091

15. Leupen SM, Besecke LM, Levine JE. Neuropeptide Y Y1-receptor stimulation is required for physiological amplification of preovulatory luteinizing hormone surges. Endocrinology. 1997;138(7):2735-2739. doi:10.1210/ endo.138.7.5223

16. Paxinos G, Watson C. The Rat Brain in Stereotaxic Coordinates. 7th ed. London: Academic Press; 2014.

17. Livak KJ, Schmittgen TD. Analysis of relative gene expression data using real-time quantitative PCR and the 2(-Delta Delta C(T)) Method. Methods. 2001;25(4):402408. doi:10.1006/meth.2001.1262

18. Varndell IM, Polak JM, Allen JM, Terenghi G, Bloom SR. Neuropeptide tyrosine (NPY) immunoreactivity in norepinephrine-containing cells and nerves of the mammalian adrenal gland. Endocrinology. 1984;114(4):1460-1462. doi:10.1210/endo-114-4-1460

19. Parker SL, Kalra SP, Crowley WR. Neuropeptide Y modulates the binding of a gonadotropin-releasing hormone $(\mathrm{GnRH})$ analog to anterior pituitary $\mathrm{GnRH}$ receptor sites. Endocrinology. 1991;128(5):2309-2316 
doi:10.1210/endo-128-5-2309

20. Azizi V, Oryan S, Khazali H, Hosseini A. The involvement of kisspeptin in centrally regulatory mechanism of neuropeptide $\mathrm{Y}$ on testosterone secretion in male Wistar rats. Physiol Pharmacol. 2016;20(4):267-276.

21. Bauer-Dantoin AC, Urban JH, Levine JE. Neuropeptide Y gene expression in the arcuate nucleus is increased during preovulatory luteinizing hormone surges. Endocrinology. 1992;131(6):2953-2958. doi:10.1210/endo.131.6.1446633

22. Crowley WR, Hassid A, Kalra SP. Neuropeptide Y enhances the release of luteinizing hormone (LH) induced by LHreleasing hormone. Endocrinology. 1987;120(3):941-945. doi:10.1210/endo-120-3-941

23. Dyer CJ, Simmons JM, Matteri RL, Keisler DH. Effects of an intravenous injection of NPY on leptin and NPY-Y1 receptor mRNA expression in ovine adipose tissue. Domest Anim Endocrinol. 1997;14(5):325-333. doi:10.1016/s07397240(97)00029-5

24. Hill JW, Urban JH, Xu M, Levine JE. Estrogen Induces Neuropeptide Y (NPY) Y1 receptor gene expression and responsiveness to NPY in gonadotrope-enriched pituitary cell cultures. Endocrinology. 2004;145(5):2283-2290. doi:10.1210/en.2003-1368

25. Castellano JM, Navarro VM, Fernandez-Fernandez R, et al. Changes in hypothalamic KiSS-1 system and restoration of pubertal activation of the reproductive axis by kisspeptin in undernutrition. Endocrinology. 2005;146(9):3917-3925. doi:10.1210/en.2005-0337

26. Forbes S, Li XF, Kinsey-Jones J, O'Byrne K. Effects of ghrelin on Kisspeptin mRNA expression in the hypothalamic medial preoptic area and pulsatile luteinising hormone secretion in the female rat. Neurosci Lett. 2009;460(2):143147. doi:10.1016/j.neulet.2009.05.060

27. Wahab F, Aziz F, Irfan S, Zaman WU, Shahab M. Shortterm fasting attenuates the response of the HPG axis to kisspeptin challenge in the adult male rhesus monkey (Macaca mulatta). Life Sci. 2008;83(19-20):633-637. doi:10.1016/j.lfs.2008.09.001

28. Smith JT, Acohido BV, Clifton DK, Steiner RA. KiSS-1 neurones are direct targets for leptin in the ob/ob mouse. J Neuroendocrinol. 2006;18(4):298-303. doi:10.1111/j.13652826.2006.01417.x

29. Quennell JH, Howell CS, Roa J, Augustine RA, Grattan DR, Anderson GM. Leptin deficiency and diet-induced obesity reduce hypothalamic kisspeptin expression in mice. Endocrinology. 2011;152(4):1541-1550. doi:10.1210/ en.2010-1100

30. Raposinho PD, Broqua P, Hayward A, et al. Stimulation of the gonadotropic axis by the neuropeptide $\mathrm{Y}$ receptor Y1 antagonist/Y4 agonist 1229U91 in the male rat. Neuroendocrinology. 2000;71(1):2-7. doi: $10.1159 / 000054514$ 